Review

\title{
Prognostic significance of neutrophil-to-lymphocyte ratio in biliary tract cancers: a systematic review and meta-analysis
}

\author{
Haowen Tang ${ }^{1, *}$, Wenping Lu ${ }^{1, *}$, Bingmin $\mathrm{Li}^{2,}{ }^{*}$, Chonghui Li ${ }^{1}$, Yinzhe $\mathrm{Xu}^{1}$ and Jiahong \\ Dong ${ }^{1,3}$ \\ ${ }^{1}$ Hospital and Institute of Hepatobiliary Surgery, Chinese PLA General Hospital, Chinese PLA Medical School, Haidian, \\ Beijing, China \\ ${ }^{2}$ Chinese PLA Medical School, Haidian, Beijing, China \\ ${ }^{3}$ Center for Hepatopancreatobiliary Diseases, Beijing Tsinghua Changgung Hospital, Tsinghua University Medical Center, \\ Changping, Beijing, China \\ * These authors have contributed equally to this work \\ Correspondence to: Jiahong Dong, email: dongjh301@163.com \\ Keywords: neutrophil-lymphocyte ratio; biliary tract cancer; overall survival; relapse free survival; prognosis \\ Received: December 27, $2016 \quad$ Accepted: February 28, $2017 \quad$ Published: March 12, 2017
}

Copyright: Tang et al. This is an open-access article distributed under the terms of the Creative Commons Attribution License (CC-BY), which permits unrestricted use, distribution, and reproduction in any medium, provided the original author and source are credited.

\section{ABSTRACT}

Background: Inflammation was considered to perform crucial roles in the development and metastasis of malignancies. A heightened neutrophil-lymphocyte ratio has been described to be associated with detrimental survivals in different malignancies. Debate remains over the impact of heightened neutrophil-lymphocyte ratio on survivals in biliary tract cancer. The review evaluated the prognostic value of neutrophil-lymphocyte ratio in biliary tract cancer.

Methods: MEDLINE, the Cochrane Library, EMBASE, and the Chinese SinoMed were systematically searched for relevant articles. Associations between neutrophillymphocyte ratio and long-term outcomes were expressed as the hazard ratios and $95 \%$ confidence intervals. The odds ratio was utilized to assess the association between neutrophil-lymphocyte ratio and clinicopathological parameters.

Results: Fourteen studies consisting of 3217 patients were analyzed: 1278 $(39.73 \%)$ in the high pretreatment neutrophil-lymphocyte ratio group and 1939 $(60.27 \%)$ in the low pretreatment neutrophil-lymphocyte ratio one. The results proved that heightened pretreatment neutrophil-lymphocyte ratio was significantly associated with detrimental overall survival and relapse free survival for biliary tract cancer patients. In addition, elevated neutrophil-lymphocyte ratio was positively correlated with higher carbohydrate antigen 19-9 levels, advanced TNM staging and greater lymph node involvement.

Conclusion: This meta-analysis marked that an increased pretreatment neutrophil-lymphocyte ratio was significantly linked with detrimental long-term outcomes and clinicopathological parameters for patients with biliary tract cancer.

\section{INTRODUCTION}

Biliary tract cancer (BTC) encompasses a heterogeneous collective of malignant neoplasms arising from the epithelium of the whole biliary system, the spectrum of which includes cholangiocarcinoma and gallbladder carcinoma (GBC) [1-3]. As one of the common causes of cancer deaths worldwide, BTC features early lymph node and distant metastases and thus carries poor survival outcomes [4-6]. The recent years have witnessed a gradual increase in incidence and mortality of BTC worldwide [7, 8]. In spite of improvements in therapeutic strategies, the prognosis of BTC still stays disappointing, with a five-year survival rate of $10-20 \%$ [9-11] and a median survival of less than one year for unresectable or metastatic BTC $[12,13]$. Given this, to 
find out a dependable prognostic marker for BTC patients is of much essential.

Inflammatory response was considered to perform crucial roles in tumor development and metastasis [14, 15]. Increasing evidence suggested systemic inflammation correlated with unfavorable survivals in a number of cancers [16-19]. Heightened amounts of proinflammatory cytokines and signaling components in patients with malignancies for one aspect might mirror disease activity and body's natural response to the tumor [20], for another aspect would facilitate the formation of new blood vessels and lymphatic vessels [14, 21]. In particular, BTC development and progression have been reported to be closely mediated by chronic biliary inflammation caused by gallstones, chronic hepatitis, etc [22-25]. Thus, inflammatory markers might possibly be used as valuable prognostic predictors for BTC patients. Neutrophillymphocyte ratio (NLR) mirroring primary immune response to diverse pathogen-derived or cancer-derived stimuli has been identified as a valuable predictor with prognostic sense, and detrimental long-term outcomes were commonly linked with the elevation of NLR in different tumors [26-31]. Additionally, our previous work has confirmed the prognostic value of NLR elevation in colorectal liver metastasis [31].

Yet, debate remains over the impact of heightened NLR on long-term survival in BTC. Prior researches had produced inconsistent results about the prognostic role of NLR. Lin G and colleagues argued that the elevation of NLR value was incrementally associated with decreased overall survival (OS) for BTC patients [32], while other report failed to identify that prognostic role [33]. In this case, a meta-analysis aiming to review the predictive value of NLR for BTC was performed. Furthermore, the association between NLR values and clinicopathological parameters was analyzed.

\section{RESULTS}

\section{Study selection and patients characteristics}

Figure 1 shows the process of study selection. A total of 53 references were produced using the outlined search strategy. After application of selection criteria, 14

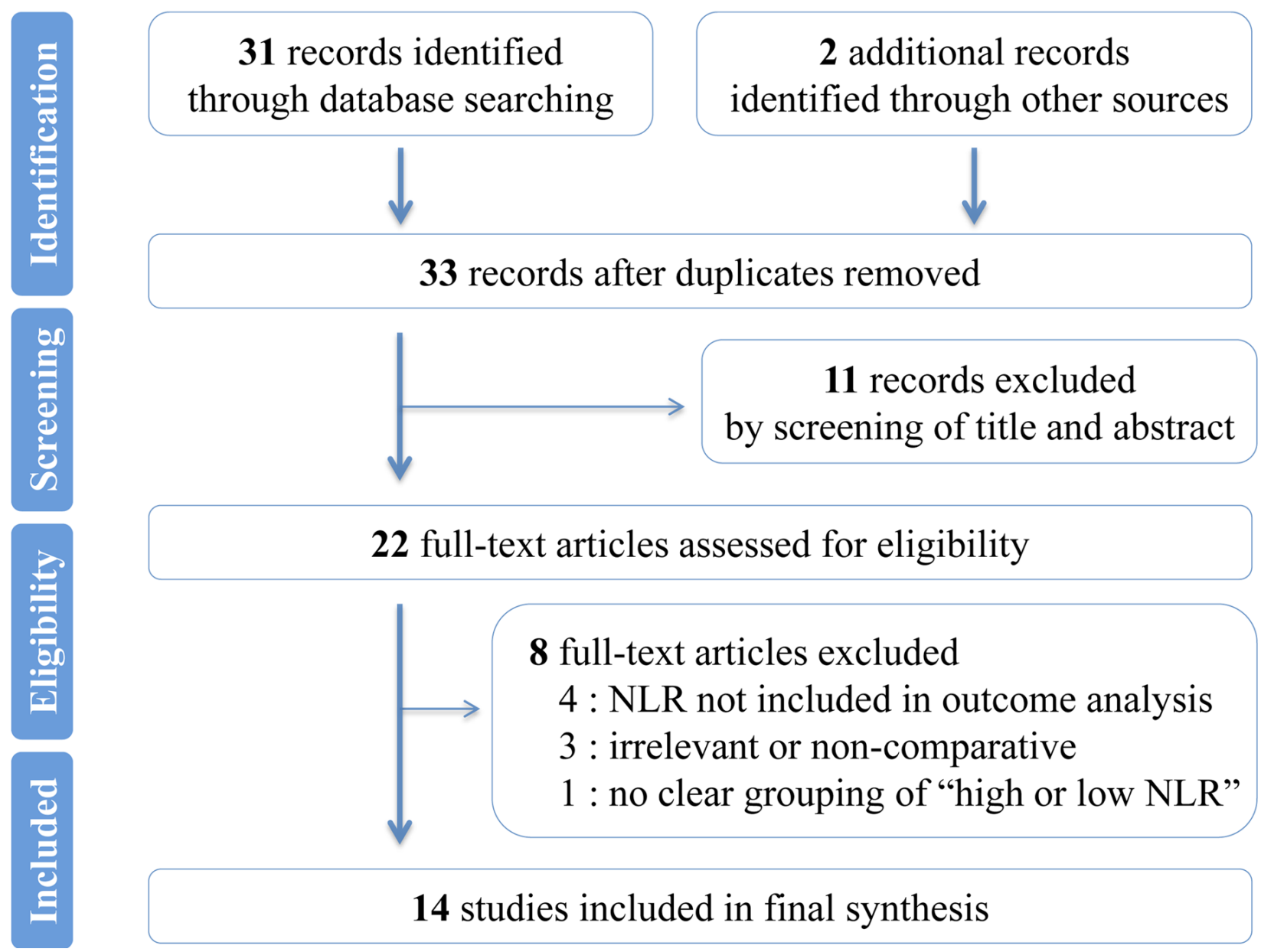

Figure 1: Flowchart of literature search. Flowchart showing selection of eligible articles. 
Table 1: Characteristics of included studies

\begin{tabular}{|c|c|c|c|c|c|c|c|c|c|c|c|c|c|c|c|}
\hline \multirow{2}{*}{ First author } & \multirow{2}{*}{ Year } & \multirow{2}{*}{ Type } & \multirow{2}{*}{ Region } & \multirow{2}{*}{ Period } & \multicolumn{4}{|c|}{ Patients characteristics } & \multirow{2}{*}{$\begin{array}{c}\text { Tumor } \\
\text { type }\end{array}$} & \multirow{2}{*}{$\begin{array}{l}\text { Treatment } \\
\text { (n) }\end{array}$} & \multicolumn{2}{|c|}{ NLR } & \multirow{2}{*}{$\begin{array}{l}\text { End } \\
\text { point }\end{array}$} & \multirow{2}{*}{$\begin{array}{l}\text { Maximum } \\
\text { follow-up } \\
\text { (months) }\end{array}$} & \multirow{2}{*}{$\begin{array}{l}\text { NOS } \\
\text { score }\end{array}$} \\
\hline & & & & & Total & $\begin{array}{c}\text { Age } \\
(\mathrm{M} \pm \mathrm{SD})\end{array}$ & $\begin{array}{c}\text { Male } \\
(\%)\end{array}$ & $\begin{array}{c}\text { High } \\
\text { NLR (n) }\end{array}$ & & & $\begin{array}{l}\text { Cut } \\
\text { off }\end{array}$ & $\begin{array}{l}\text { Sample } \\
\text { time, site }\end{array}$ & & & \\
\hline Lee $\mathrm{BS}^{37}$ & 2016 & $\mathrm{R}$ & South Korea & $2004-2013$ & 221 & $62 \pm 10$ & 69.23 & 171 & $\mathrm{CC}$ & Chemo & 5 & PT, PB & OS & 120 & 7 \\
\hline Okuno $\mathrm{M}^{38}$ & 2016 & $\mathrm{R}$ & Japan & $2000-2013$ & 534 & $66 \pm 10$ & 62.92 & 39 & $\mathrm{CC}$ & SR & 5 & PT, PB & OS & $78(9-174)$ & 7 \\
\hline $\operatorname{Lin} G^{32}$ & 2016 & $\mathrm{R}$ & China & 1999-2011 & 102 & $>50(n=67)$ & 64.71 & 43 & $\mathrm{CC}$ & SR & 3 & PT, PB & $\begin{array}{c}\text { OS } \\
\text { RFS }\end{array}$ & 120 & 7 \\
\hline $\mathrm{Li} \mathrm{H}^{39}$ & 2015 & $\mathrm{R}$ & China & 2011-2014 & 127 & $67.50 \pm 10.50$ & 56.69 & NA & BTC & $\begin{array}{l}\text { Chemo(90) } \\
\& S R(37)\end{array}$ & 3 & PT, PB & OS & $29.1(3.9-99.6) \dagger$ & 6 \\
\hline Zhang $\mathrm{Y}^{40}$ & 2015 & $\mathrm{R}$ & China & $2001-2013$ & 145 & $63.54 \pm 10.46$ & 46.90 & 83 & GBC & SR & 1.94 & PT, PB & Os & 100 & 6 \\
\hline Chen $Q^{41}$ & 2015 & $\mathrm{R}$ & China & $2005-2011$ & 322 & 58 & 60.25 & 194 & $\mathrm{CC}$ & SR & 2.49 & PT, PB & $\begin{array}{c}\text { OS } \\
\text { RFS }\end{array}$ & 80 & 6 \\
\hline Gao $H_{Y}^{42, \#}$ & 2015 & $\mathrm{R}$ & China & $2007-2010$ & 90 & $53.60(35-87) \uparrow$ & 52.22 & 16 & GBC & SR & 5 & PT, PB & OS & 100 & 6 \\
\hline Grenader $\mathrm{T}^{43}$ & 2015 & $P$ & $\begin{array}{l}\text { The UK } \\
\text { \&Japan }\end{array}$ & $2002-2008$ & 462 & $64.30(23-83) \dagger$ & 50.22 & 134 & BTC & Chemo & 3 & PT, PB & OS & 48 & 6 \\
\hline Iwaku $\mathrm{A}^{44}$ & 2014 & $\mathrm{R}$ & Japan & $2005-2013$ & 52 & $79(52-96) \dagger$ & 59.62 & 26 & BTC & Chemo & 4 & PT, PB & OS & 80 & 6 \\
\hline McNamara $\mathrm{MG}^{45}$ & 2014 & $\mathrm{R}$ & Canada & $1987-2012$ & 864 & $65(23-93) \dagger$ & 51.39 & 478 & BTC & $\begin{array}{c}\text { Chemo(538) } \\
\text { \&SR(326) }\end{array}$ & 3 & PT, PB & OS & $14.4(5.6-27.6) \dagger$ & 8 \\
\hline Liu $Y^{46, \#}$ & 2014 & $\mathrm{R}$ & China & $2002-2011$ & 96 & $54.80(20-76) \uparrow$ & 66.67 & 55 & $\mathrm{CC}$ & SR & 2.5 & PT, PB & $\begin{array}{c}\text { OS } \\
\text { RFS }\end{array}$ & 120 & 7 \\
\hline $\mathrm{Wu} \mathrm{XS}{ }^{47}$ & 2014 & $\mathrm{R}$ & China & $2000-2010$ & 85 & $\leq 70(\mathrm{n}=48)$ & 34.12 & 45 & GBC & SR & 2.3 & PT, PB & OS & $16(2-87) \dagger$ & 6 \\
\hline Dumitrascu $\mathrm{T}^{48}$ & 2013 & $\mathrm{R}$ & Romania & $1996-2012$ & 90 & $57.50(24-77) \dagger$ & 57.78 & NA & $\mathrm{CC}$ & SR & 3.3 & PT, PB & $\begin{array}{c}\text { OS } \\
\text { RFS }\end{array}$ & $68(6-143) \dagger$ & 7 \\
\hline Gomez $\mathrm{D}^{18}$ & 2008 & $P$ & The UK & $1996-2006$ & 27 & $57(32-84) \dagger$ & 33.33 & 11 & $\mathrm{CC}$ & SR & 5 & PT, PB & $\begin{array}{c}\text { OS } \\
\text { RFS } \\
\end{array}$ & $23(14-72) \dagger$ & 6 \\
\hline
\end{tabular}

NLR: neutrophil-lymphocyte ratio; NOS score: Newcastle-Ottawa Scale score; R: retrospective; P: prospective; CC: cholangiocarcinoma; BTC: biliary tract cancer; GBC: gallbladder carcinoma; Chemo: chemotherapy; SR: surgical resection; PT: pretreatment; PB: peripheral blood; OS: overall survival; RFS: recurrence free survival; NA: not available; \&: and. M \pm SD: mean \pm standard deviation; $\Phi:$ value is mean with or wihtout range in parenthesis; $\uparrow:$ value is median with range in parenthesis; \# : studies from the database of the Chinese SinoMed.

studies qualified for inclusion in the present meta-analysis $[18,32,34-45]$. Twelve were retrospective studies and two were prospective; the majority (12) of the studies were published in English and two were in Chinese (from the Chinese SinoMed). The studies were carried out in the UK (one study), Romania (one study), Canada (one study), Republic of Korea (one study), Japan (two studies), or China (seven studies) or that were multicenter (the UK and Japan, one study) between 2008 and 2016. Two studies each divided their patients into two cohorts: surgical resection cohort and chemotherapy cohort; one study divided the included patients into the UK cohort and Japan cohort. A total of 3217 patients were analyzed, consisting of $1278(39.73 \%)$ in the high pretreatment NLR group and $1939(60.27 \%)$ in the low pretreatment NLR one. For all the studies, a median of 114.50 patients (range 27-864) were recruited. For the majority of the studies, the median age and median male percentage was 62.77 years (range 53.6-79) and 54.24\% (range 33.33-69.23\%), respectively. Of all the patients analyzed, 1854 in 11 studies (11 cohorts) received surgical resection and 1363 in five studies (five cohorts) took palliative chemotherapy. The maximum follow-up periods ranged from 48 to 180 months. NLR were all assessed before treatment. Baseline characteristics were presented in Table 1; a summary of main findings were provided in Table 2.

\section{NLR and OS}

All the 14 studies investigated the relationship between NLR and OS in BTC. The synthesized HR for high pretreatment NLR group was 1.51 (95\% CI 1.361.67) in comparison with the low pretreatment NLR group (heterogeneity: $\mathrm{I}^{2} 14.10 \%, P=0.30$ ), which implied that an elevation in pretreatment NLR significantly correlated with unfavorable OS for BTC patients (Figure 2).

\section{NLR and RFS}

Five studies documented the relationship between NLR and RFS. The synthesized HR for the high pretreatment NLR group was of statistical sense (HR 1.46, 95\% CI 1.18-1.81; heterogeneity: $\mathrm{I}^{2} 41.40 \%, P=0.15$ ), which signified that BTC patients with high pretreatment NLR carried detrimental RFS (Figure 3).

\section{Subgroup analyses and meta-regression}

According to the five predefined parameters, we planned subgroup analyses in an attempt to explore the relationship between NLR and prognosis. As to OS, results of all ten subgroup analyses consistently demonstrated that patients with low pretreatment NLR carried survival 
Table 2: Results of meta-analysis on prognostic significance of NLR in BTCs

\begin{tabular}{|c|c|c|c|c|c|c|c|c|c|c|c|c|c|}
\hline & \multicolumn{7}{|c|}{ Overall Survival } & \multicolumn{6}{|c|}{ Recurrence Free Survival } \\
\hline & $\begin{array}{c}\text { No. } \\
\text { studies }\end{array}$ & $\begin{array}{c}\text { No. } \\
\text { patients }\end{array}$ & HR & $95 \% \mathrm{CI}$ & $I^{2}, \%$ & $\begin{array}{l}\text { P value for } \\
\text { heterogeneity }\end{array}$ & $\begin{array}{c}\text { P value for } \\
\text { meta-regression }\end{array}$ & $\begin{array}{c}\text { No. } \\
\text { studies }\end{array}$ & $\begin{array}{c}\text { No. } \\
\text { patients }\end{array}$ & HR & $95 \%$ CI & $I^{2}, \%$ & $\begin{array}{c}\text { P value for } \\
\text { heterogeneity }\end{array}$ \\
\hline Overall & 14 & 3217 & 1.51 & $1.36-1.67$ & 14.10 & 0.30 & & 5 & 637 & 1.46 & $1.18-1.81$ & 41.40 & 0.15 \\
\hline Type of cancer & & & & & & & 0.74 & & & & & & \\
\hline $\mathrm{CC}$ & 7 & 1392 & 1.53 & $1.31-1.77$ & 0.00 & 0.56 & & 5 & 637 & 1.46 & $1.18-1.81$ & 41.40 & 0.15 \\
\hline GBC & 4 & 1184 & 1.64 & $1.08-2.50$ & 68.70 & 0.02 & & 0 & 0 & - & - & - & - \\
\hline $\begin{array}{l}\text { Treatment } \\
\text { methods }\end{array}$ & & & & & & & 0.40 & & & & & & \\
\hline Surgical resection & 10 & 1817 & 1.49 & $1.29-1.72$ & 14.20 & 0.31 & & 5 & 637 & 1.46 & $1.18-1.81$ & 41.40 & 0.15 \\
\hline Chemotherapy & 4 & 1273 & 1.53 & $1.29-1.82$ & 37.40 & 0.19 & & 0 & 0 & - & - & - & - \\
\hline $\begin{array}{l}\text { Sample } \\
\text { size }\end{array}$ & & & & & & & 0.28 & & & & & & \\
\hline$\geq 100$ & 8 & 2777 & 1.50 & $1.29-1.73$ & 0.38 & 0.13 & & 2 & 424 & 1.59 & $0.90-2.80$ & 66.20 & 0.09 \\
\hline$<100$ & 6 & 440 & 1.56 & $1.29-1.88$ & 0.00 & 0.63 & & 3 & 213 & 1.46 & $1.09-1.95$ & 48.00 & 0.15 \\
\hline $\begin{array}{l}\text { NLR } \\
\text { cutoff }\end{array}$ & & & & & & & 0.06 & & & & & & \\
\hline$\geq 3$ & 10 & 2569 & 1.45 & $1.28-1.66$ & 24.00 & 0.22 & & 3 & 219 & 1.79 & $1.12-2.85$ & 67.10 & 0.05 \\
\hline$<3$ & 4 & 648 & 1.73 & $1.40-2.14$ & 0.00 & 0.87 & & 2 & 418 & 1.29 & $1.03-1.63$ & 0.00 & 0.75 \\
\hline Geographic area & & & & & & & 0.25 & & & & & & \\
\hline Asian & 11 & 1857 & 1.67 & $1.45-1.93$ & 4.70 & 0.40 & & 3 & 520 & 1.43 & $1.08-1.88$ & 33.40 & 0.22 \\
\hline Non-Asian & 4 & 1360 & 1.36 & $1.20-1.54$ & 0.00 & 0.49 & & 2 & 117 & 1.65 & $0.90-3.05$ & 73.90 & 0.05 \\
\hline
\end{tabular}

NLR: neutrophil-lymphocyte ratio; HR: hazard ratio; CI: confidence interval; CC: cholangiocarcinoma; GBC: gallbladder carcinoma.

Study

ES $(95 \% \mathrm{Cl}) \quad$ Weight

ID

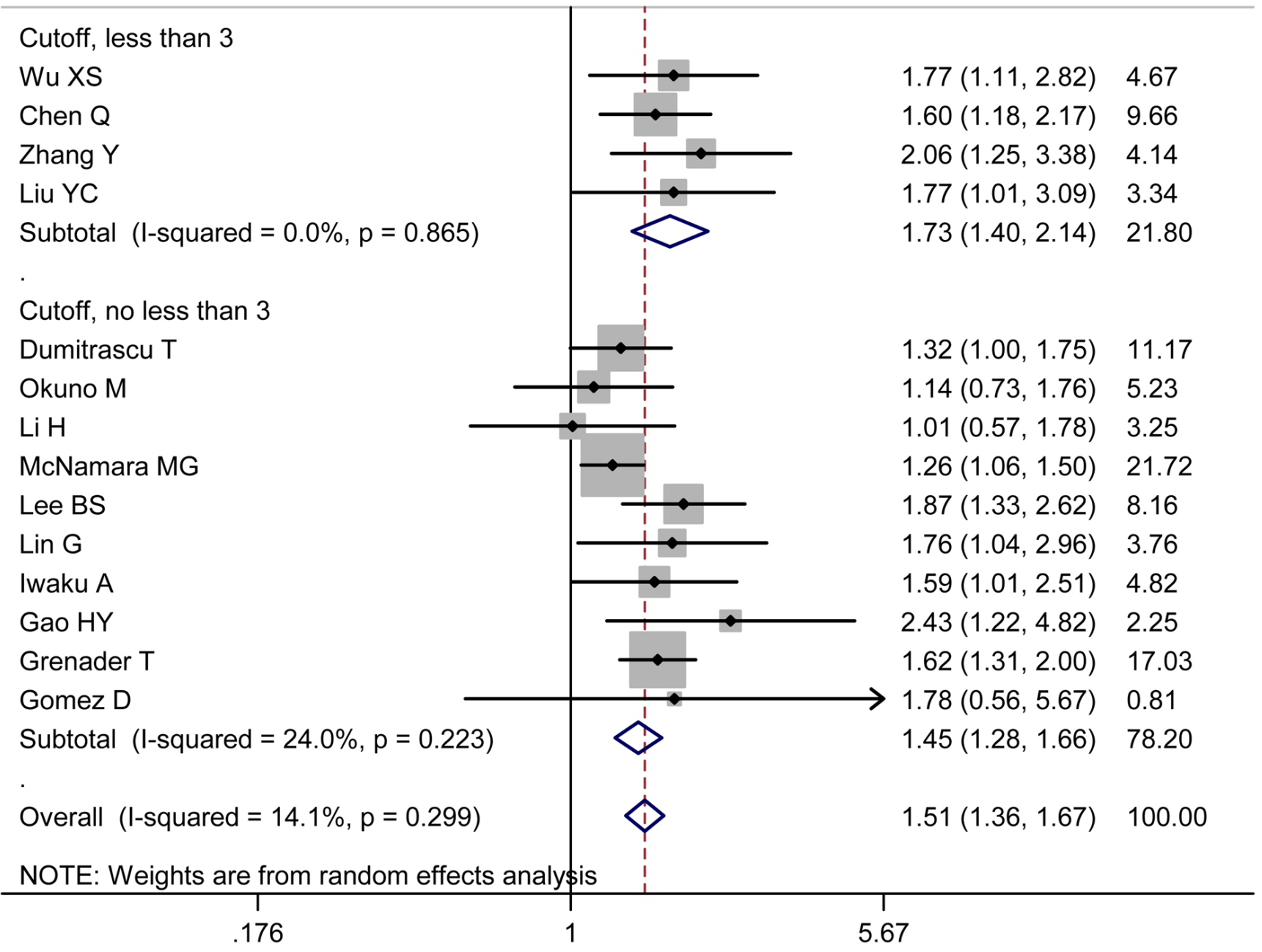

Figure 2: Pooled HR value for OS. By subgroups of NLR cutoff value (value $\geq 3$ and value $<3$ ) Each square and horizontal bar shows the HR for that trial comparison and corresponding $95 \% \mathrm{CI}$, respectively; the size of squares denotes study weight. The diamond represents the pooled HR (random effect model); the center of diamond represents the HR with the extremities denoting the $95 \%$ CI. 
superiority. With respect to RFS, subgroup analyses were performed based on eight predefined parameters (type of cancer: CC, predominant treatment arm: surgical resection, sample size: size $\geq 100$ and size $<100$, NLR cutoff value: value $\geq 3$ and value $<3$, and geographic area: Asian and non-Asian). Subgroup analyses of GBC and chemotherapy were not performed for lack of relevant or enough data. As a result, similar results were achieved, except that no substantial differences in RFS were detected between high NLR and low NLR groups in the subgroups with a sample size $\geq 100$ (HR 1.59, 95\% CI 0.90-2.80) and with patients from non-Asian geographic area (HR 1.65, 95\% CI 0.90-3.05). Results of the meta-regression analysis for OS (type of cancer, $P=0.74$; predominant treatment arm, $P=0.71$; sample size, $P=0.28$; NLR cutoff value, $P=0.06$; geographic area, $P=0.25$ ) confirmed that the heterogeneity among studies was slight. However, metaregression analysis for RFS was not conducted for limited studies for inclusion, which was best suitable for analyzing at least ten studies. A summary of the above-mentioned results were provided in Table 2 .

\section{Association between NLR and clinicopathological parameters}

Association between NLR and carbohydrate antigen 19-9 (CA199) level were documented in four studies. The pooled result demonstrated a significant correlation between elevated pretreatment NLR and higher CA199 level (Figure 4A, OR 1.54, 95\% CI 1.13-2.11; heterogeneity: $\left.\mathrm{I}^{2} 0.00 \%, P=0.99\right)$.

As to the correlation between NLR and tumor differentiation, pooled analysis of five studies produced an OR of 1.36 favoring high NLR group (heterogeneity: $\left.\mathrm{I}^{2} 11.10 \%, P=0.34\right)$; however, corresponding 95\% CI ranged from 0.97 to 1.91 (Figure 4B), which indicated that correlations between high NLR and poorer differentiation were with marginal significance.

With regards to TNM staging, relevant parameters from five studies were pooled. The combined OR of 2.60 (Figure 4C, 95\% CI 1.84-3.68; heterogeneity: $\mathrm{I}^{2} 0.00 \%, P$ $=0.55$ ) illustrated a propensity of heightened pretreatment NLR towards an advanced TNM staging.

In addition, information on NLR and lymph node involvement in BTC patients were extracted from five studies. A similar propensity of lymph node involvement favoring elevated NLR group was also presented (Figure 4D, OR 2.20, 95\% CI 1.50-3.21) with slight betweenstudy heterogeneity $\left(\mathrm{I}^{2} 3.20 \%, P=0.39\right)$.

\section{Analysis of sensitivity and test for publication bias}

The results of sensitivity analyses identified no substantial changes in HR values, with a range from 1.47

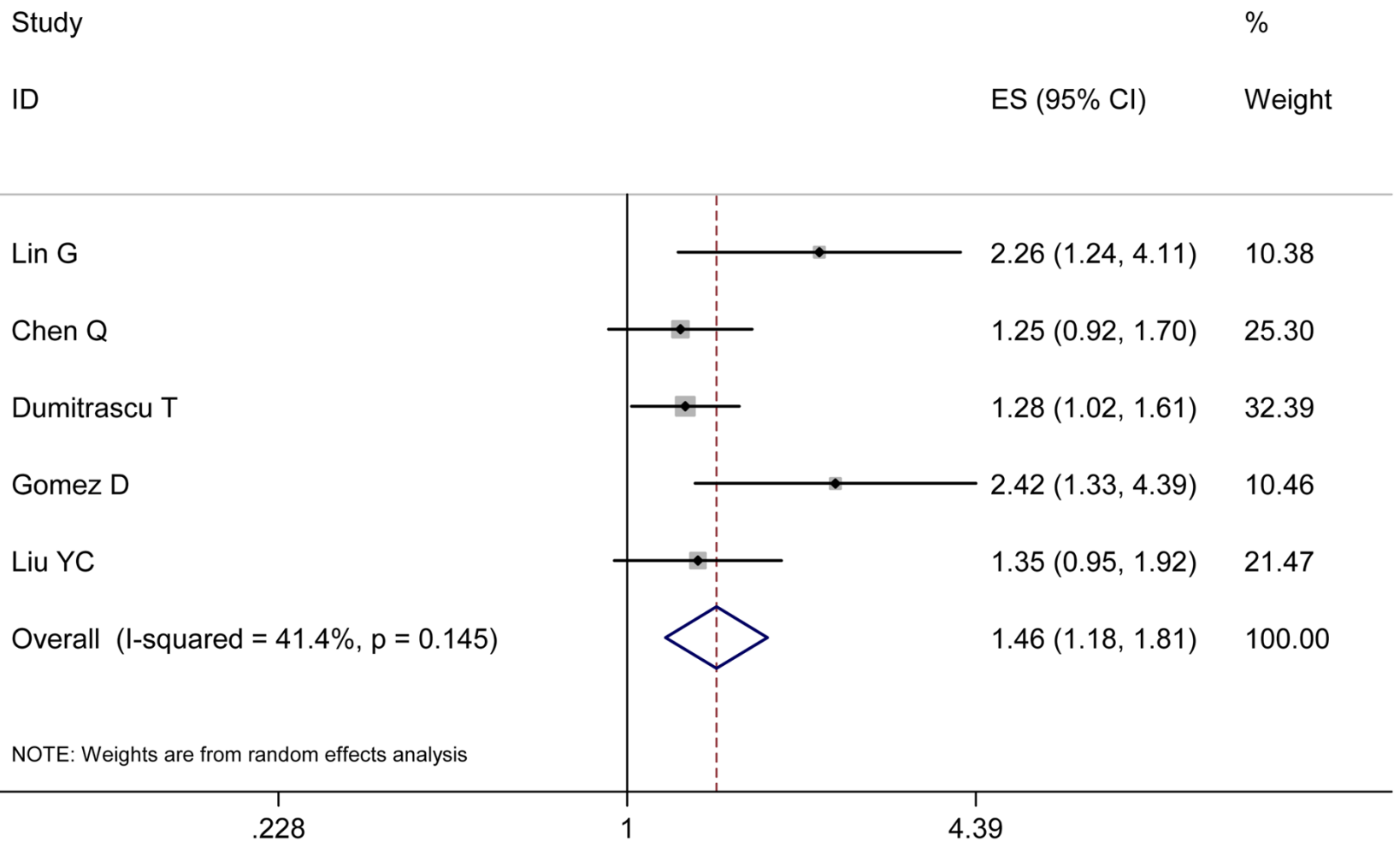

Figure 3: Results of the meta-analysis on pooled HR values for RFS. Each square and horizontal bar shows the HR for that trial comparison and corresponding $95 \% \mathrm{CI}$, respectively; the size of squares denotes study weight. The diamond represents the pooled HR (random effect model); the center of diamond represents the HR with the extremities denoting the 95\% CI. 
to 1.58 of HRs in OS (Figure 5) and a range from 1.29 to 1.47 of HRs in RFS. The result of Eegg's test $(P=0.14)$ showed no existence of evident publication bias, with Begg's funnel plot demonstrated a symmetric distribution (Figure 6).

\section{DISCUSSION}

The prognostic significance of NLR has been described in certain malignancies recently. Yet, predictive value of NLR in BTC stays controversial. The present study, to our best knowledge, serves as the first metaanalysis exploring the correlation between NLR and long-term outcomes as well as clinicopathological parameters in BTC patients. The results proved that heightened pretreatment NLR was significantly associated with detrimental OS and RFS for BTC patients. The heterogeneity among studies was slight, . Commensurate results were obtained in most of subgroup analyses: Consistent findings were identified by sensitivity analysis. Also, significant associations between NLR and CA199 level, TNM staging and lymph node involvement were detected.

The definite mechanisms for the relationship between NLR elevation and survival inferiorities for BTC patients have not been fully studied. And the following aspects might explain the correlation.

In our study, elevated NLR was found to be positively correlated with higher CA199 levels, advanced TNM staging and greater lymph node involvement. Regarding BTC, such characteristics has been proven to be linked with tumor invasiveness and metastasis [46], and considered as independent predictors for poor survival outcome. Herein, these findings could partially reflect the prognostic value of increased NLR. In addition, excessive or prolonged chronic inflammation tended to trigger cancerogenesis of normal cells [15]. Earlier studies have shown that inflammation, by stimulating angiogenesis and causing localized immunosuppression, will promote and accelerate the formation of a suitable microenvironment where the survival, expansion, accumulation of successive mutations, and epigenetic changes of premalignant cells

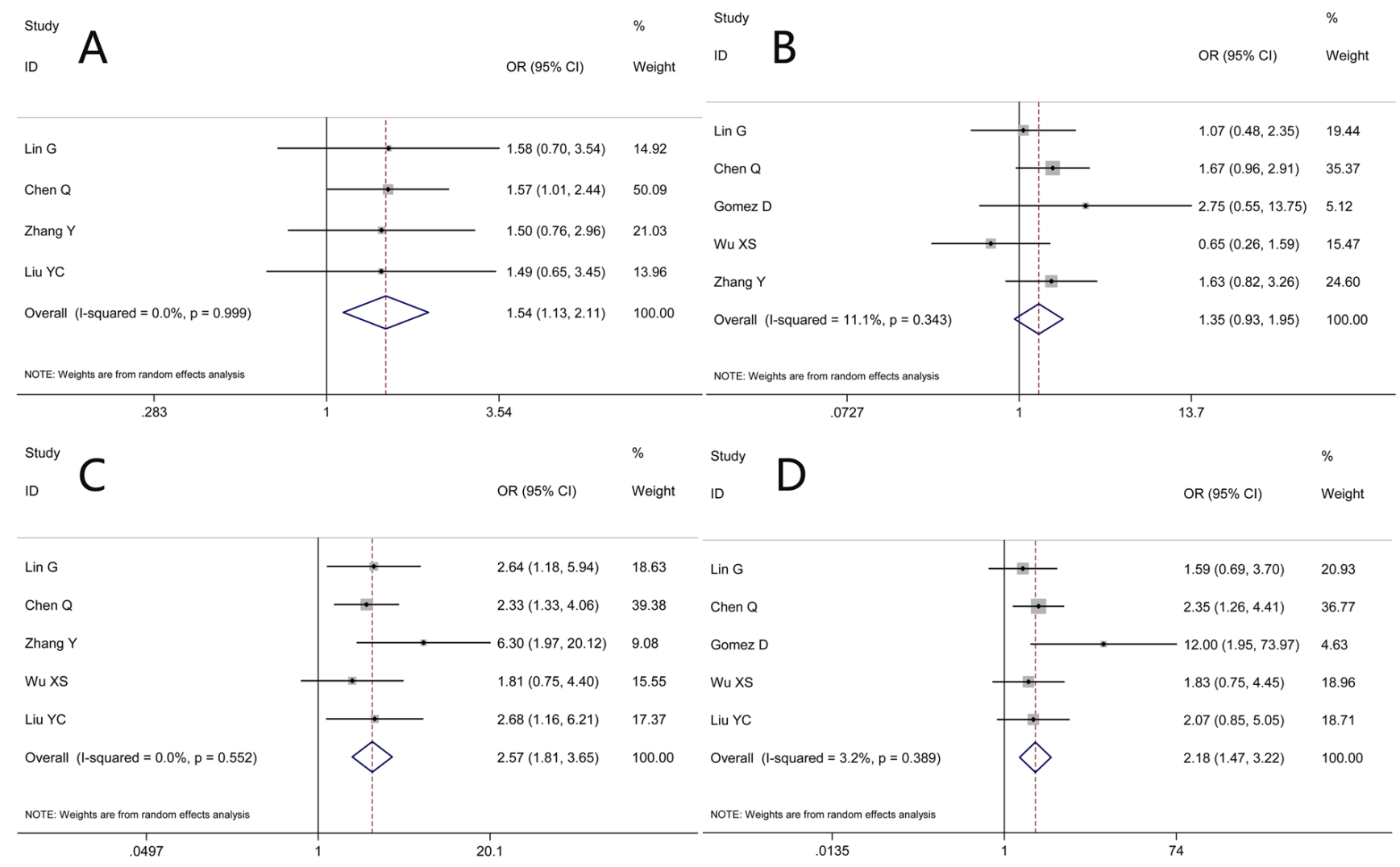

Figure 4: Results of studies on the associations between elevated NLR and clinicopathological parameters. Figure 4A implies the association between NLR and pretreatment carbohydrate antigen 19-9 (CA199) level, the result demonstrating a significant correlation between elevated pretreatment NLR and higher CA199 level with no between-study heterogeneity. Figure 4B implies the association between pretreatment NLR and tumor differentiation, the result demonstrating that associations between high NLR values and poorer differentiation were with marginal significance. Figure 4C implies the association between pretreatment NLR and TNM staging, indicating a propensity of heightened pretreatment NLR towards an advanced TNM staging. Figure 4D implies the association pretreatment NLR and lymph node involvement; a similar propensity of lymph node involvement favoring elevated NLR group was presented with slight between-study heterogeneity. 
could be facilitated [47]. As above mentioned, most of the risk factors for BTC including gallstones and chronic hepatitis might cause such inflammatory response and induce a chronic tissue damage/inflammation mechanism that closely mediates BTC development and progression [22-24]. Recent researches have reflected that NLR signifies the balance between immunosurveillance (function of anti-tumor immune) and tumor-promoting inflammation (activation of pro-tumor inflammatory pathway). Neutrophils are recognized as the primary source of vascular endothelial growth factor, which serves as an angiogenic mediator involved in tumor angiogenesis, and thusly promoted the development and proliferation of malignancy [48-50]. At the meantime, neutrophil elevation prompts the secretion of cytokines and chemokines, thus expediting tumor proliferation [15, 19]. Inhibition of interleukin-6 has been reported to specifically pose a growth-inhibition effect on cholangiocarcinoma cell line, and interleukin- 6 overexpression will lead to activation of AKT and anti-apoptotic protein myeloid cell leukemia-1 [51]. Comparatively, lymphocytes, as an indispensable mediator in anti-tumor activity, will cause cytotoxic cell death and cytokine production to eliminate tumor cells [52]. It has been described by Ropponen KM that heightened amounts of tumor-infiltrating lymphocytes independently help foresee favorable survival in colorectal cancer [53]; lymphocyte reduction denoted a suppressed or weakened antitumor immune response [54]. Furthermore, it was illustrated in vitro that peripheral blood neutrophil elevation retarded the cytolytic activity of lymphocytes and natural killer cells to tumor cells [55]. Thus, rise of NLR, caused by either a heightened amount of neutrophil or a decreased level of lymphocyte, symbolized the potential inhibition of body's immunosurveillance and antitumor immune response. To sum up, the abovementioned aspects might be responsible for the result that BTC patients with high NLR featured survival inferiority. This was in close agreement with the findings from McNamara MG who documented that increased pretreatment NLR ascribed to excessive inflammatory response and weakened anti-tumor immunity was significantly linked with poor prognosis in BTC patients. Median survival durations for high NLR patients (NLR $\geq$ $3)$ and low NLR patients (NLR $<3$ ) were 12 months and 21.6 months, respectively [42].

Subgroup analyses suggested that prognostic values of elevated NLR for unfavorable OS were obtained in accordance with all ten predefined parameters. Notably,

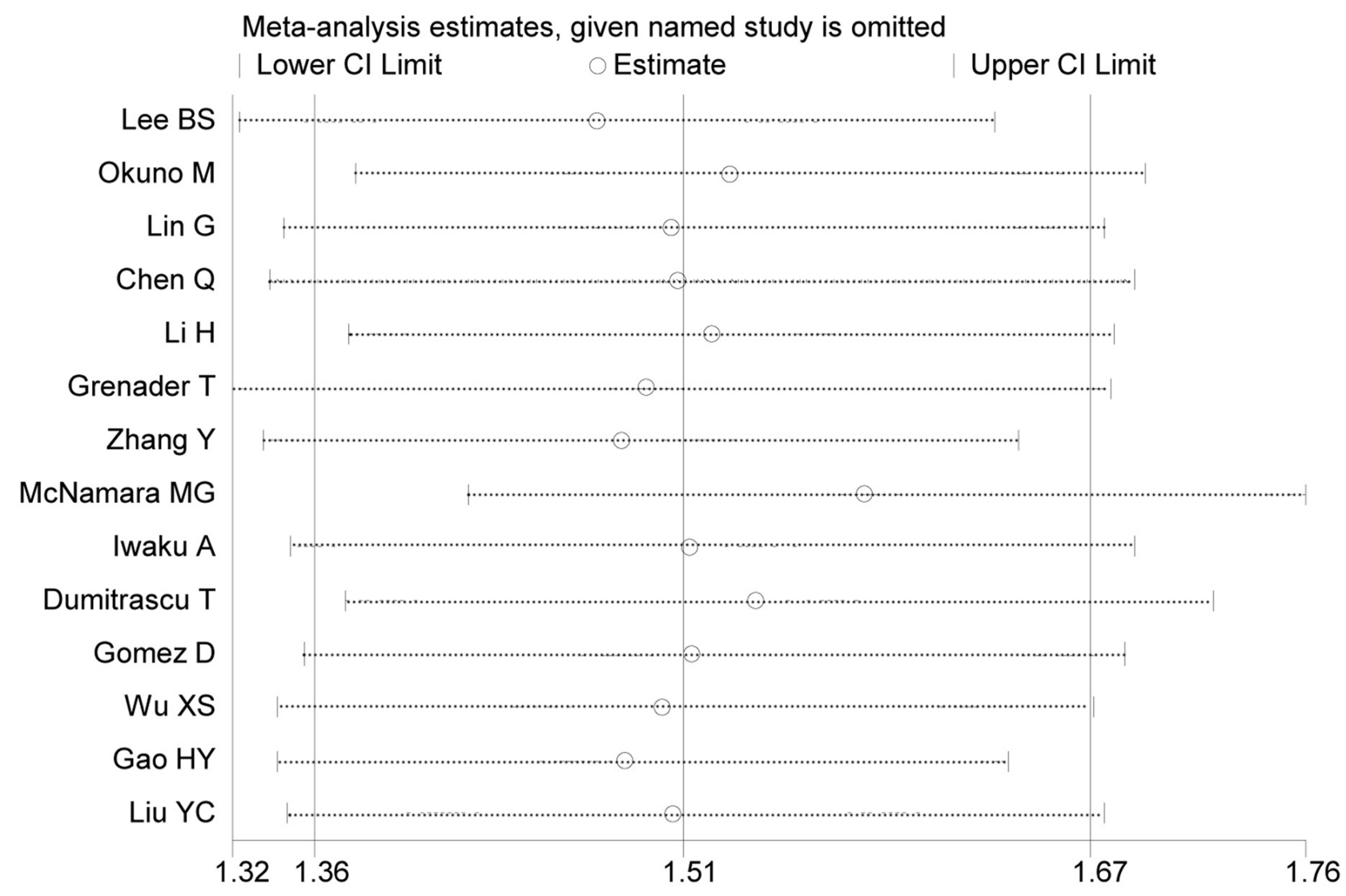

Figure 5: Result of sensitivity analysis for OS. The middle vertical line denotes the pooled HR, and the two vertical lines describe $95 \%$ CI. The middle small circle and two ends of the dotted lines indicates the pooled HR and 95\% CI, respectively, when the study on the left was deleted at a time. 
although parallel findings of subgroup estimations for RFS were identified by the majority of predefined parameters, negative prognostic significances of elevated NLR were obtained in the subgroups with a sample size $\geq 100$ (HR 1.59 , 95\% CI 0.90-2.80) and with patients from nonAsian geographic area (HR 1.65, 95\% CI 0.90-3.05). Such unmatched performances could be in part explained by the small sizes of included studies for analyses (only two studies for each) and obvious between-study heterogeneities in the pooled analyses ( $\mathrm{I}^{2}$ equals to $66.20 \%$ and $73.90 \%$, respectively).

In addition, NLR took advantages of fast access, widespread availability and economical reproducibility over other laboratory markers. As was shown by our result, a heightened NLR strongly correlated with worse OS and RFS in patients with BTC. Hence, NLR can be regularly surveyed as a prognostic marker for patients with BTC, irrespective of therapeutic arms (surgical resection or chemotherapy) and geographic area (Asian and nonAsian).

There were three main strengths in the present review. (1) The present study, to our best knowledge, serves as the first meta-analysis exploring the correlation between NLR and long-term outcomes as well as clinicopathological parameters in BTC patients. (2) Using relatively strict study selection criteria, a substantial retrospective cohort of 3217 patients were included and analyzed. (3) Heterogeneity in our meta-analysis was slight $\left(\mathrm{I}^{2} 14.10 \%, P=0.30\right)$, and commensurate results were accordingly obtained by both subgroup and sensitivity analyses.

Despite of the strengths aforementioned, this review carried the following limitations. The primary limitation was that the majority of the included cohorts were retrospective, thus inevitably influencing the precision of the results. Besides, variations in NLR cutoff values (ranged from 1.94 to 5) possibly exacerbated heterogeneity and bias, which restricted its general application. Furthermore, certain HRs and corresponding 95\% CIs (two for both OS and RFS) were retrieved from univariate analyses because of unavailability of these values from multivariate analyses and absences of the authors' replies. The consistency, accuracy and statistical power of results might be impaired. Finally, the size of the studies included for the pooled estimate of RFS, particularly the subgroup analysis according to predefined parameters, was rather small, which was more susceptible to certain biases.

\section{CONCLUSIONS}

In conclusion, the present review indicated that an increased pretreatment NLR was significantly linked with detrimental long-term outcomes (OS and RFS) and clinicopathological parameters for patients with BTC.

\section{Begg's funnel plot with pseudo 95\% confidence limits}

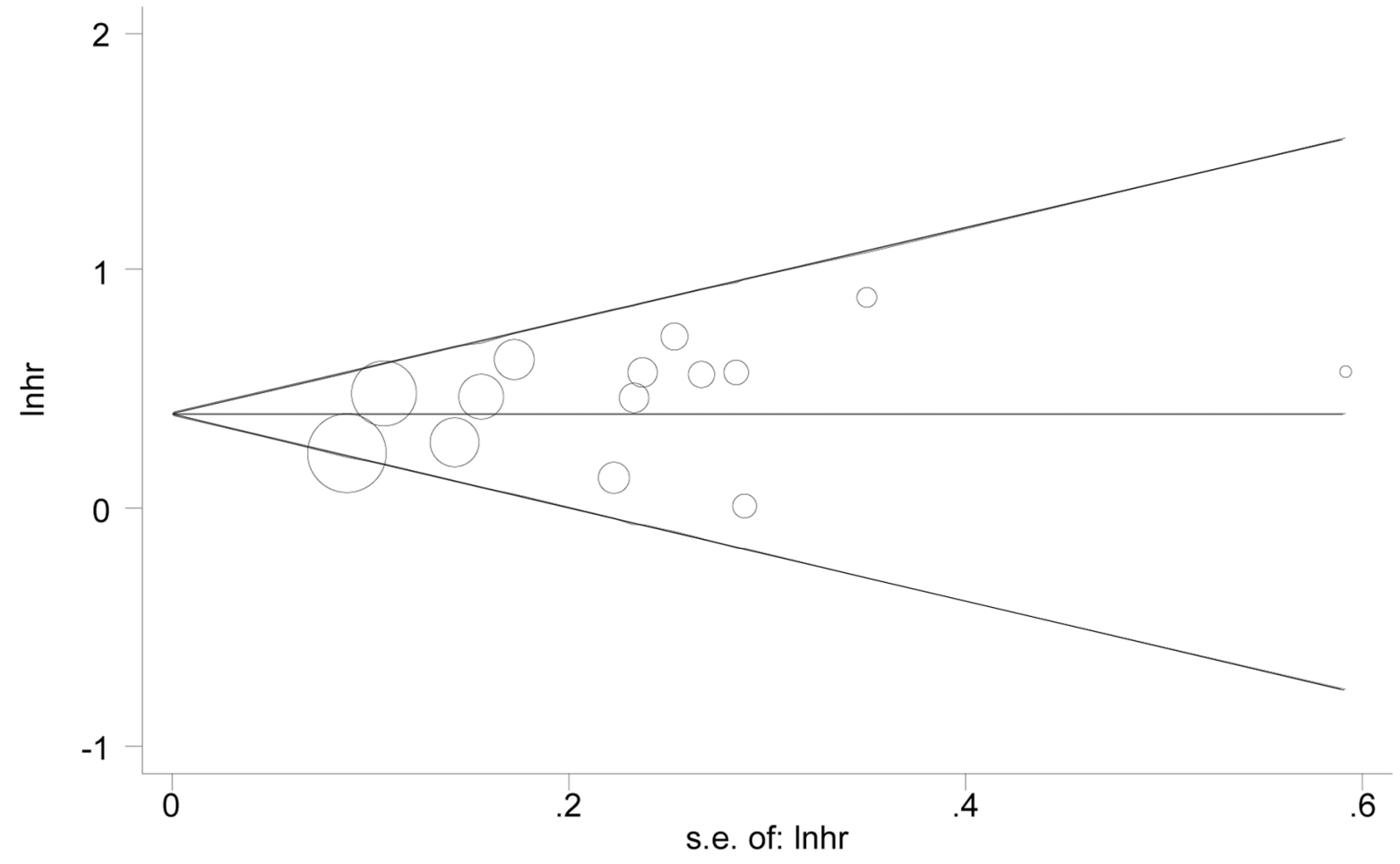

Figure 6: Begg's funnel plot to evaluate OS. Begg's funnel plot demonstrated a symmetric distribution showing no existence of evident publication bias for OS. 
Thus, NLR, as a cost-effective and widely available marker with prognostic value, could be regularly surveyed in BTC patients receiving either surgical resection or chemotherapy. Further multicenter and high-quality studies will be needed to support the argument and find out the best NLR cutoff.

\section{MATERIALS AND METHODS}

The meta-analysis was performed in compliance with the Meta-analysis of Observational Studies in Epidemiology group (MOOSE) guidelines [56].

\section{Study identification}

For this review, four electronic databases (MEDLINE (via PubMed), the Cochrane Library, EMBASE, and the Chinese SinoMed (http://www. sinomed.ac.cn/zh/)) were systematically searched from the initiation of the databases until September 2016. No language restriction was applied to the search strategy. Search terms (medical subject headings or keywords) included: "Bile Duct Neoplasms," "Cholangiocarcinoma," "Common Bile Duct Neoplasms," "Bile Duct Cancer," "Biliary Tract Cancer or Neoplasms," "Gallbladder Cancer, Neoplasm or Carcinoma," "Cholecyst Cancer, Neoplasm or Carcinoma," "Neutrophil-lymphocyte (Ratio)," "Neutrophil (to) Lymphocyte (Ratio)," and "NLR." Furthermore, reference lists of retrieved studies were searched manually. In the presence of repeated papers by authors on the same data set, the latest or most informative was included. The most recent search was done on September 29, 2016. The following selection (inclusion and exclusion) criteria were established in the present meta-analysis.

Inclusion criteria were as follows (i) patient were diagnosed as having BTC (cholangiocarcinoma or GBC) by pathology. (ii) inclusion of pretreatment NLR as a component in final outcome analysis. (iii) clear statement of NLR cutoff. A study fulfilling all three inclusion criteria was regarded eligible to be included. And exclusion criteria were (i) researches focusing on cell assay or animal model. (ii) reviews, letters, comments, case reports and editorials (iii) overlapping or duplicate publications. (iiii) hazard ratio (HR) investigating correlation between pretreatment NLR and long-term survivals unavailable or unobtainable. A study matching any of the four exclusion criteria was ruled out.

\section{Data abstraction}

Two reporters (HW T and BM L) separately abstracted following information from each eligible study using a standardized sheet. Predefined parameters were as follows: study identifier (first author and year of publication); essential study data (study type and region, recruitment period, type of cancer, predominant treatment arms, total number of subjects, the site and time of sampling, NLR cutoff, patient number with increased NLR, monitoring endpoint, HR and confidence interval (CI), and follow-up period); and baseline characteristics of subjects (patient age and male patient percentage, etc.). In the absences of HR, CI, or other vital data from a study, the corresponding author of the study was inquired by email. When failing to get a response, we utilized the methods described by Tierney to digitize and derive the relevant survival estimate [57].

\section{Definition}

Cholangiocarcinoma included three broad categories according to anatomical location (intrahepatic, hilar and extrahepatic) [4]. NLR was calculated from the differential count by dividing the serum absolute neutrophil count by the serum absolute lymphocyte count in peripheral blood [58]. OS referred to the interval between medical interventions and death or the final observation for surviving patients. Relapse free survival (RFS) was calculated from the time of curative treatment until the detection of tumor relapse (recurrence). Tumor differentiation was rigorously stratified according to the British Society of Gastroenterology guidelines on the management of BTC as well/moderated and poorly differentiation. Tumor grade was described using the TNM staging system (American Joint Committee on Cancer $7^{\text {th }}$ edn) as grade I/II and III/IV. Newcastle-Ottawa Scale (NOS) was utilized for the quality assessment for articles included by examining three aspects (method of patient selection, comparability of the study groups, and assessment of outcomes reported). Articles achieving six or more stars were acknowledged to be of good quality. $P$ $<0.05$ was acknowledged statistically significant.

\section{Outcomes comparison and statistical analysis}

Associations between NLR and long-term outcomes (OS and RFS) were expressed as the HR and a corresponding $95 \% \mathrm{CI}$. An HR above one represented a survival benefit favoring low pretreatment NLR group (reference group). The odds ratio (OR) was utilized as the effective value to assess the association between NLR values and clinicopathological parameters.

Analyses were conducted using STATA statistical software (version 12.0, Stata Corporation, College Station, TX, USA). Cochrane's Q and $\mathrm{I}^{2}$ tests were performed to evaluate heterogeneity among studies. Random effect models were used because of heterogeneities among studies. Begg's funnel plot and Egger's test were used to examine the publication bias. Sensitivity analysis was conducted in which one study was deleted 
at a time. An attempt to explain heterogeneity was made using subgroup analyses and meta-regression in accordance with predefined parameters: type of cancer (cholangiocarcinoma and GBC), predominant treatment arm (surgical resection and chemotherapy), sample size (size $\geq 100$ and size $<100$ ), NLR cutoff value (value $\geq$ 3 and value $<3$ ), and geographic area (Asian and nonAsian).

\section{Abbreviations}

NLR: neutrophil-lymphocyte ratio; NOS score: Newcastle-Ottawa Scale score; BTC: biliary tract cancer; GBC: gallbladder carcinoma; OS: overall survival; RFS: relapse free survival; CA199: carbohydrate antigen 19-9.

\section{Author contributions}

HW and BM carried out most of vital stages of the analysis including literature search, data abstraction, statistical analysis, manuscript completion and submission. $\mathrm{CH}$ and $\mathrm{YZ}$ conducted critical revision. JH and WP designed the project and analyzed the results. All authors reviewed and approved the final manuscript.

\section{ACKNOWLEDGMENTS}

The work is supported by the National Key Technology R\&D Program of China (NO. 2012BAI06B01) and the National S\&T Major Project for Infectious Diseases of China (NO. 2012ZX10002-017). In addition, we gratefully acknowledge the statistical assistance of Professor Dan Feng from Department of Medical Statistics, Chinese PLA General Hospital, Chinese PLA Medical School.

\section{CONFLICTS OF INTEREST}

There is no conflict of interest.

\section{GRANT SUPPORT}

The work is supported by the National Key Technology R\&D Program of China (NO. 2012BAI06B01) and the National S\&T Major Project for Infectious Diseases of China (NO. 2012ZX10002-017).

\section{REFERENCES}

1. Fong Y, Dong J. Hepatobiliary Cancer. USA: People's Medical Publishing House; 2014.

2. Li ZS, Li Q. [The latest 2010 WHO classification of tumors of digestive system]. [Article in Chinese]. Zhonghua Bing Li Xue Za Zhi. 2011; 40:351-54.
3. Fusco N, Bosari S. HER2 aberrations and heterogeneity in cancers of the digestive system: implications for pathologists and gastroenterologists. World J Gastroenterol. 2016; 22:7926-37.

4. Razumilava N, Gores GJ. Cholangiocarcinoma. Lancet. $2014 ; 383: 2168-79$.

5. Hezel AF, Deshpande V, Zhu AX. Genetics of biliary tract cancers and emerging targeted therapies. J Clin Oncol. 2010; 28:3531-40.

6. Cai Y, Cheng N, Ye H, Li F, Song P, Tang W. The current management of cholangiocarcinoma: A comparison of current guidelines. Biosci Trends. 2016; 10:92-102.

7. Siegel RL, Miller KD, Jemal A. Cancer statistics, 2015. CA Cancer J Clin. 2015; 65:5-29.

8. Vasilieva LE, Papadhimitriou SI, Dourakis SP. Modern diagnostic approaches to cholangiocarcinoma. Hepatobiliary Pancreat Dis Int. 2012; 11:349-59.

9. Lepage C, Capocaccia R, Hackl M, Lemmens V, Molina E, Pierannunzio D, Sant M, Trama A, Faivre J; EUROCARE-5 Working Group. Survival in patients with primary liver cancer, gallbladder and extrahepatic biliary tract cancer and pancreatic cancer in Europe 1999-2007: results of EUROCARE-5. Eur J Cancer. 2015 Sep 5. doi: 10.1016/j. ejca.2015.07.034. [Epub ahead of print]

10. Miyakawa S, Ishihara S, Horiguchi A, Takada T, Miyazaki M, Nagakawa T. Biliary tract cancer treatment: 5,584 results from the Biliary Tract Cancer Statistics Registry from 1998 to 2004 in Japan. J Hepatobiliary Pancreat Surg. 2009; 16:1-7.

11. Brandi G, Farioli A, Astolfi A, Biasco G, Tavolari S. Genetic heterogeneity in cholangiocarcinoma: a major challenge for targeted therapies. Oncotarget. 2015; 6:14744-53. doi: 10.18632/oncotarget.4539.

12. Park I, Lee JL, Ryu MH, Kim TW, Sook Lee S, Hyun Park D, Soo Lee S, Wan Seo D, Koo Lee S, Kim MH. Prognostic factors and predictive model in patients with advanced biliary tract adenocarcinoma receiving first-line palliative chemotherapy. Cancer. 2009; 115:4148-55.

13. Hsing AW, Gao YT, Devesa SS, Jin F, Fraumeni JF Jr. Rising incidence of biliary tract cancers in Shanghai, China. Int J Cancer. 1998; 75:368-70.

14. Coussens LM, Werb Z. Inflammation and cancer. Nature. 2002; 420:860-67.

15. Mantovani A, Allavena P, Sica A, Balkwill F. Cancerrelated inflammation. Nature. 2008; 454:436-44.

16. Proctor MJ, Talwar D, Balmar SM, O'Reilly DS, Foulis AK, Horgan PG, Morrison DS, McMillan DC. The relationship between the presence and site of cancer, an inflammation-based prognostic score and biochemical parameters. Initial results of the Glasgow Inflammation Outcome Study. Br J Cancer. 2010; 103:870-76.

17. Szkandera J, Gerger A, Liegl-Atzwanger B, Absenger G, Stotz M, Samonigg H, Maurer-Ertl W, Stojakovic T, Ploner F, Leithner A, Pichler M. Validation of the prognostic 
relevance of plasma C-reactive protein levels in soft-tissue sarcoma patients. Br J Cancer. 2013; 109:2316-22.

18. Gomez D, Morris-Stiff G, Toogood GJ, Lodge JP, Prasad KR. Impact of systemic inflammation on outcome following resection for intrahepatic cholangiocarcinoma. J Surg Oncol. 2008; 97:513-18.

19. Balkwill F, Mantovani A. Inflammation and cancer: back to Virchow? Lancet. 2001; 357:539-45.

20. Minardi D, Scartozzi M, Montesi L, Santoni M, Burattini L, Bianconi M, Lacetera V, Milanese G, Cascinu S, Muzzonigro G. Neutrophil-to-lymphocyte ratio may be associated with the outcome in patients with prostate cancer. Springerplus. 2015; 4:255.

21. Mouta C, Heroult M. Inflammatory triggers of lymphangiogenesis. Lymphat Res Biol. 2003; 1:201-18.

22. Rizvi S, Gores GJ. Pathogenesis, diagnosis, and management of cholangiocarcinoma. Gastroenterology. 2013; 145:1215-29.

23. Lee CH, Chang CJ, Lin YJ, Yeh CN, Chen MF, Hsieh SY. Viral hepatitis-associated intrahepatic cholangiocarcinoma shares common disease processes with hepatocellular carcinoma. Br J Cancer. 2009; 100:1765-70.

24. El-Serag HB, Engels EA, Landgren O, Chiao E, Henderson L, Amaratunge HC, Giordano TP. Risk of hepatobiliary and pancreatic cancers after hepatitis $\mathrm{C}$ virus infection: $\mathrm{A}$ population-based study of U.S. veterans. Hepatology. 2009; 49:116-23.

25. Yamashita S, Arita J, Sasaki T, Kaneko J, Aoki T, Beck Y, Sugawara Y, Hasegawa K, Kokudo N. Intrahepatic cholangiocarcinoma with intrahepatic biliary lithiasis arising 47 years after the excision of a congenital biliary dilatation: report of a case. Biosci Trends. 2012; 6:98-102.

26. Absenger G, Szkandera J, Pichler M, Stotz M, Arminger F, Weissmueller M, Schaberl-Moser R, Samonigg H, Stojakovic T, Gerger A. A derived neutrophil to lymphocyte ratio predicts clinical outcome in stage II and III colon cancer patients. Br J Cancer. 2013; 109:395-400.

27. Xiao WK, Chen D, Li SQ, Fu SJ, Peng BG, Liang LJ. Prognostic significance of neutrophil-lymphocyte ratio in hepatocellular carcinoma: a meta-analysis. BMC Cancer. 2014; 14:117.

28. Stotz M, Gerger A, Eisner F, Szkandera J, Loibner H, Ress AL, Kornprat P, AlZoughbi W, Seggewies FS, Lackner C, Stojakovic T, Samonigg H, Hoefler G, Pichler M. Increased neutrophil-lymphocyte ratio is a poor prognostic factor in patients with primary operable and inoperable pancreatic cancer. Br J Cancer. 2013; 109:416-21.

29. Sharaiha RZ, Halazun KJ, Mirza F, Port JL, Lee PC, Neugut AI, Altorki NK, Abrams JA. Elevated preoperative neutrophil:lymphocyte ratio as a predictor of postoperative disease recurrence in esophageal cancer. Ann Surg Oncol. 2011; 18:3362-69.

30. Neal CP, Mann CD, Sutton CD, Garcea G, Ong SL, Steward WP, Dennison AR, Berry DP. Evaluation of the prognostic value of systemic inflammation and socioeconomic deprivation in patients with resectable colorectal liver metastases. Eur J Cancer. 2009; 45:56-64.

31. Tang H, Li B, Zhang A, Lu W, Xiang C, Dong J. Prognostic Significance of Neutrophil-to-Lymphocyte Ratio in Colorectal Liver Metastasis: A Systematic Review and Meta-Analysis. PLoS One. 2016; 11:e0159447.

32. Lin G, Liu Y, Li S, Mao Y, Wang J, Shuang Z, Chen J, Li S. Elevated neutrophil-to-lymphocyte ratio is an independent poor prognostic factor in patients with intrahepatic cholangiocarcinoma. Oncotarget. 2016; 7:50963-71. doi: 10.18632/oncotarget.7680.

33. Barlow AD, Garcea G, Berry DP, Rajesh A, Patel R, Metcalfe MS, Dennison AR. Staging laparoscopy for hilar cholangiocarcinoma in 100 patients. Langenbecks Arch Surg. 2013; 398:983-88.

34. Lee BS, Lee SH, Son JH, Jang DK, Chung KH, Lee YS, Paik WH, Ryu JK, Kim YT. Neutrophil-lymphocyte ratio predicts survival in patients with advanced cholangiocarcinoma on chemotherapy. Cancer Immunol Immunother. 2016; 65:141-50.

35. Okuno M, Ebata T, Yokoyama Y, Igami T, Sugawara G, Mizuno T, Yamaguchi J, Nagino M. Evaluation of inflammation-based prognostic scores in patients undergoing hepatobiliary resection for perihilar cholangiocarcinoma. J Gastroenterol. 2016; 51:153-61.

36. Li H, Zhao T, Ji X, Liang S, Wang Z, Yang Y, Yin J, Wang R. Hyperfibrinogenemia predicts poor prognosis in patients with advanced biliary tract cancer. Tumour Biol. 2016; 37:3535-42.

37. Zhang Y, Jiang C, Li J, Sun J, Qu X. Prognostic significance of preoperative neutrophil/lymphocyte ratio and platelet/ lymphocyte ratio in patients with gallbladder carcinoma. Clin Transl Oncol. 2015; 17:810-18.

38. Chen Q, Yang LX, Li XD, Yin D, Shi SM, Chen EB, Yu L, Zhou ZJ, Zhou SL, Shi YH, Fan J, Zhou J, Dai Z. The elevated preoperative neutrophil-to-lymphocyte ratio predicts poor prognosis in intrahepatic cholangiocarcinoma patients undergoing hepatectomy. Tumour Biol. 2015; 36:5283-89.

39. Gao HY, Zhang H, Xu XD, Zou WB, Lin KL, Deng YC, Liu QQ, Jiang JX, Wang M, Zhu F, Qin RY. Neutrophil-lymphocyte ratio as a prognostic factor for gallbladder carcinoma after radical resection. World Chin J Digestology. 2015; 23:5705-10.

40. Grenader T, Nash S, Plotkin Y, Furuse J, Mizuno N, Okusaka T, Wasan H, Valle J, Bridgewater J. Derived neutrophil lymphocyte ratio may predict benefit from cisplatin in the advanced biliary cancer: the ABC-02 and BT-22 studies. Ann Oncol. 2015; 26:1910-16.

41. Iwaku A, Kinoshita A, Onoda H, Fushiya N, Nishino H, Matsushima M, Tajiri H. The Glasgow Prognostic Score accurately predicts survival in patients with biliary tract cancer not indicated for surgical resection. Med Oncol. 
2014; 31:787.

42. McNamara MG, Templeton AJ, Maganti M, Walter T, Horgan AM, McKeever L, Min T, Amir E, Knox JJ. Neutrophil/lymphocyte ratio as a prognostic factor in biliary tract cancer. Eur J Cancer. 2014; 50:1581-89.

43. Liu YC, Li SH, Shuang ZY, Chen JL, Shengping L. Impact of preoperative blood neutrophil-to-lymphocyte ratio on postoperative prognosis of intrahepatic cholangiocarcinoma. Chin J Gen Surg. 2014; :160-5.

44. Wu XS, Shi LB, Li ML, Ding Q, Weng H, Wu WG, Cao Y, Bao RF, Shu YJ, Ding QC, Mu JS, Gu J, Dong P, et al. Evaluation of two inflammation-based prognostic scores in patients with resectable gallbladder carcinoma. Ann Surg Oncol. 2014; 21:449-57.

45. Dumitrascu T, Chirita D, Ionescu M, Popescu I. Resection for hilar cholangiocarcinoma: analysis of prognostic factors and the impact of systemic inflammation on long-term outcome. J Gastrointest Surg. 2013; 17:913-24.

46. de Jong MC, Nathan $\mathrm{H}$, Sotiropoulos GC, Paul A, Alexandrescu S, Marques H, Pulitano C, Barroso E, Clary BM, Aldrighetti L, Ferrone CR, Zhu AX, Bauer TW, et al. Intrahepatic cholangiocarcinoma: an international multiinstitutional analysis of prognostic factors and lymph node assessment. J Clin Oncol. 2011; 29:3140-45.

47. Grivennikov SI, Greten FR, Karin M. Immunity, inflammation, and cancer. Cell. 2010; 140:883-99.

48. Kusumanto YH, Dam WA, Hospers GA, Meijer C, Mulder NH. Platelets and granulocytes, in particular the neutrophils, form important compartments for circulating vascular endothelial growth factor. Angiogenesis. 2003; 6:283-87.

49. Jablonska J, Leschner S, Westphal K, Lienenklaus S, Weiss S. Neutrophils responsive to endogenous IFN-beta regulate tumor angiogenesis and growth in a mouse tumor model. J Clin Invest. 2010; 120:1151-64.

50. Hofman PM. Pathobiology of the neutrophil-intestinal epithelial cell interaction: role in carcinogenesis. World J Gastroenterol. 2010; 16:5790-800.
51. Park J, Tadlock L, Gores GJ, Patel T. Inhibition of interleukin 6-mediated mitogen-activated protein kinase activation attenuates growth of a cholangiocarcinoma cell line. Hepatology. 1999; 30:1128-33.

52. Shi F, Shi M, Zeng Z, Qi RZ, Liu ZW, Zhang JY, Yang YP, Tien P, Wang FS. PD-1 and PD-L1 upregulation promotes CD8(+) T-cell apoptosis and postoperative recurrence in hepatocellular carcinoma patients. Int J Cancer. 2011; 128:887-96.

53. Ropponen KM, Eskelinen MJ, Lipponen PK, Alhava E, Kosma VM. Prognostic value of tumour-infiltrating lymphocytes (TILs) in colorectal cancer. J Pathol. 1997; 182:318-24.

54. Liu S, Lachapelle J, Leung S, Gao D, Foulkes WD, Nielsen TO. CD8+ lymphocyte infiltration is an independent favorable prognostic indicator in basal-like breast cancer. Breast Cancer Res. 2012; 14:R48.

55. Fridlender ZG, Sun J, Kim S, Kapoor V, Cheng G, Ling L, Worthen GS, Albelda SM. Polarization of tumor-associated neutrophil phenotype by TGF-beta: "N1" versus "N2" TAN. Cancer Cell. 2009; 16:183-94.

56. Stroup DF, Berlin JA, Morton SC, Olkin I, Williamson GD, Rennie D, Moher D, Becker BJ, Sipe TA, Thacker SB. Meta-analysis of observational studies in epidemiology: a proposal for reporting. Meta-analysis Of Observational Studies in Epidemiology (MOOSE) group. JAMA. 2000; 283:2008-12.

57. Tierney JF, Stewart LA, Ghersi D, Burdett S, Sydes MR. Practical methods for incorporating summary time-to-event data into meta-analysis. Trials. 2007; 8:16.

58. Proctor MJ, Morrison DS, Talwar D, Balmer SM, Fletcher CD, O'Reilly DS, Foulis AK, Horgan PG, McMillan DC. A comparison of inflammation-based prognostic scores in patients with cancer. A Glasgow Inflammation Outcome Study. Eur J Cancer. 2011; 47:2633-41. 